\title{
Erratum to: Composition of weathering crusts on sandstones from natural outcrops and architectonic elements in an urban environment
}

Mariola Marszalek • Zofia Alexandrowicz • Grzegorz Rzepa

Published online: 19 December 2014

(C) Springer-Verlag Berlin Heidelberg 2014

Erratum to: Environ Sci Pollut Res (2014) 21:14023-14036

DOI 10.1007/s11356-014-3312-y

The original publication of this article contains a mistake. The correct image for Fig. 7 is shown below:

The online version of the original article can be found at http://dx.doi.org/ 10.1007/s11356-014-3312-y.

M. Marszałek $(\bowtie) \cdot G$. Rzepa

Department of Mineralogy, Petrography and Geochemistry, AGH

University of Science and Technology, al. A. Mickiewicza 30,

30-059 Kraków, Poland

e-mail: mmarszal@agh.edu.pl

G. Rzepa

e-mail: gprzepa@cyf-kr.edu.pl

\section{Z. Alexandrowicz}

Institute of Nature Conservation, Polish Academy of Sciences, al. A.

Mickiewicza 33, 31-120 Kraków, Poland

e-mail: alexandrowicz@iop.krakow.pl 
Fig. 7 Microphotographs: sandstone from natural outcrops - a outer layer covered by ferruginous compounds (sample SMC-14, 1P), b iron oxides between mineral grains (sample SMC-12, 1P), and $\mathbf{c}$ iron compounds occurring in cleavage fissures of feldspar (sample SMC14, XP); sandstone from architectonic detail— d black crust composed of gypsum covering the outer layer of the detail (sample MC-001, 1P), e gypsum crystals filling pores and cracks, replacing stone cement (sample MC-001, 1P), and f gypsum filling cleavage on feldspar (sample MC-011, XP). Optical microscope, thin sections cut perpendicular to the stone surface. 1P one polar, XP crossed polars
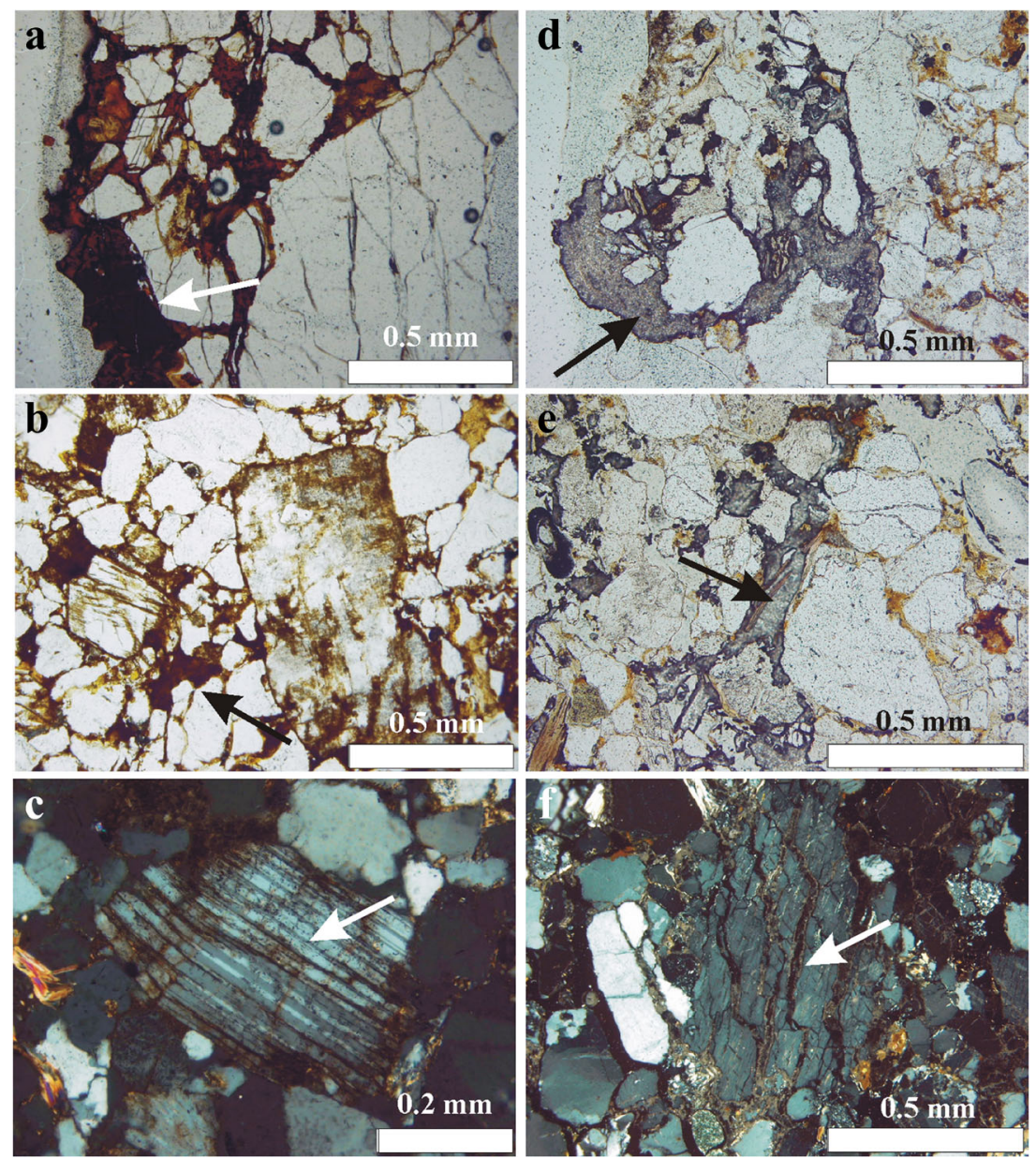